\title{
O ESTADO DA ARTE SOBRE A PESQUISA EM EDUCAÇÃO DO CAMPO NA REGIÃO NORDESTE (1998 - 2015)
}

\author{
STATE OF THE ART ON RESEARCH IN THE FIELD OF RURAL EDUCATION IN \\ NORTHEAST REGION (1998 - 2015)
}
EL ESTADO DEL ARTE SOBRE LA INVESTIGACIÓN EN EDUCACIÓN DEL CAM- PO EN LA REGIÓN NORESTE (1998 - 2015)

\author{
Emerson Augusto de Medeiros \\ Professor Assistente da Universidade Federal Rural do Semi-Árido - UFERSA. \\ Doutorando em Educação da Universidade Estadual do Ceará - UECE. \\ emerson.medeiros@ufersa.edu.br
}

Ana Maria lório Dias Professora Doutora da Universidade Federal do Ceará - UFC. ana.iorio@yahoo.com.br

\begin{abstract}
RESUMO: O presente estudo emerge de uma pesquisa arrolada no Doutorado em Educação do Programa de Pós-Graduação em Educação da Universidade Estadual do Ceará - UECE. Como objetivo central, vislumbramos evidenciar a produção científica desenvolvida na pós-graduação em educação da Região Nordeste sobre a Educação do Campo, no período de 1998 a 2015. Como objeto de análise, apontamos as teses e as dissertações produzidas e publicadas nos 18 programas e cursos de pós-graduação em educação em nível de Mestrado (acadêmico e profissional) e de Doutorado, de universidades da região aludida. Atentamos ao mapeamento das temáticas investigadas, das tendências teóricas e dos aportes metodológicos caracterizados nas produções. Como resultado do estudo, referenciamos que os trabalhos analisados atentam para temáticas que estão diretamente ligadas à realidade e aos problemas inerentes à educação do campo: formação de professores, políticas educacionais, movimentos sociais do campo, educação rural, educação profissional, dentre outras. Os aportes teóricos se centralizam na literatura nacional. Destacamos, além disso, a não utilização de artigos, teses, dissertações e outros gêneros textuais científicos nas discussões. No tocante aos aspectos metodológicos, aludimos que a abordagem qualitativa se referencia na grande maioria das produções, entrelaçando-se aos estudos de carácter etnográfico, exploratório e à modalidade estudo de caso.
\end{abstract}

PALAVRAS-CHAVE: Educação do Campo. Estado da Arte. Educação do Campo na Região Nordeste.

ABSTRACT: This study emerges from a survey the Doctorate in Education Program of Graduate Studies in Education at the State University of Ceará - UECE. It highlight the scientific production developed in graduate education in the Northeast Region on Rural Education, from 1998 to 2015. As the object of analysis, we point the theses and dissertations published in 18 programs courses graduate education at Master's level (academic and professional) and Doctorate in universities of the mentioned region. Alert to the mapping of the investigated issues, the theoretical trends and methodological contributions featured in productions. As a result of the study, pointed out that the studies analyzed pay attention to issues that are directly linked to the reality and the problems of rural education: teacher training, education policy, rural social movements, rural education, vocational education, among others. The theoretical contributions are centered in the national literature. We point out, moreover, non-use of articles, reviews, and other scientific genres in the discussions. With regard to methodological aspects the qualitative approach is referenced in most productions, intertwining to ethnographic studies, exploratory study and the type of case.

KEYWORDS: Rural Education. State of the art. Rural Education in the Northeast Region.

Artigo recebido em setembro de 2015

Aprovado em novembro de 2015

Cad. Pes., São Luís, v. 22, n. 3, set./dez. 2015 
RESUMEN: El presente estudio emerge de una investigación presentada en el Doctorado en Educación del Programa de Posgrado de la Universidad del Estado de Ceará - UECE. Como objetivo principal, decidimos evidenciar la producción científica desarrollada en los cursos de posgrado en educación de la Región Nordeste sobre la Educación del Campo, en el periodo de 1998 a 2015. Como objeto de análisis, señalamos las tesis y disertaciones producidas y publicadas en 18 programas y cursos de posgrado a nivel de Maestría (académica y profesional) y Doctorado, de las universidades de la región mencionada. Alertamos para uno mapeo de las temáticas investigadas, de las tendencias teóricas y de los aportes metodológicos caracterizados en las producciones. Como resultado del estudio, percibimos que los trabajos tiene atentado a las temáticas que están directamente ligadas a realidad y a los problemas pertenecientes a la educación del campo: formación de profesorado, políticas educacionales, movimientos sociales del campo, educación rural, educación profesional, entre otras. Los aportes teóricos se centralizan en la literatura nacional. Señalamos, por otra parte, la no utilización de artículos, tesis, disertaciones y otros géneros científicos en las discusiones. Con respecto a los aspectos metodológicos, aludimos que la abordaje cualitativo se referencia en la gran mayoría de las producciones, entrelazándose a los estudios de carácter etnográficos, exploratorio y a la modalidad de estudio de caso.

PALABRAS CLAVE: Educación del Campo. Estado del Arte. Educación del Campo en la Región Nordeste. 


\section{1 | INTRODUÇÃO}

Este trabalho versa sobre o estado da arte acerca da pesquisa em Educação do Campo, com o objetivo de apresentar a produção científica acumulada sobre a temática na Região Nordeste, tendo como marco temporal para a construção da investigação o período de 1998 a 2015. Como referência para análise dos dados, utilizamos as teses e as dissertações produzidas e publicados nos/pelos programas de pós-graduação em educação da referida região".

Estudos acerca do estado da arte são construídos e publicados em diversas áreas do saber, evidenciando um inventário significativo de conhecimentos que foram produzidos e socializados em pesquisas, em tempos e espaços em que se desenvolvem as discussões. (SILVA; NÓBREGATHERRIEN; FARIAS, 2013; FERRREIRA, 2002; LEITINHO; DIAS, 2014).

No tocante a este artigo, a intenção é a de propiciar reflexões a respeito de contribuições de pesquisadores da educação, no âmbito da educação do campo, na Região Nordeste. Pensamos em delimitar o estudo, no que concerne ao recorte geográfico (Região Nordeste), devido à amplitude da investigação, a qual dificulta uma análise interpretativa e significativa sobre o tema.

Entendemos o estado da arte como um estudo que tenciona "mapear e discutir uma certa produção acadêmica em determinado campo do conhecimento, utilizando predominantemente fontes de consulta disponíveis na forma de resumos ou catálogos" (FERREIRA, 2002, p. 258). Nesse caminho, a autora relaciona o estado da arte a "uma metodologia de caráter inventariante e descritivo da produção acadêmica e científica sobre o tema que se busca investigar" (FERREIRA, 2002, p. 258).

Lembramos que $o$ interesse em inventariar os estudos produzidos e publicados com ênfase na educação do campo deu-se em virtude de a temática ser central no trabalho de doutoramento, que se encontra em andamento no Programa de Pós-graduação em Educação da Universidade Estadual do Ceará - UECE.

Antes de iniciar a pesquisa, aclaramos que buscamos o banco de dados da Biblioteca Digital Brasileira de Teses e Dissertações - BDTD, a fim de identificar o quantitativo de trabalhos existentes no acervo sobre a educação do campo, no recorte temporal expresso $(1998-2015)$. O total encontrado, entre dissertações e teses, foi de 8.525 publicações: 2.422 teses e 6.103 dissertações ${ }^{2}$. Alertamos que ao adentrar na leitura dos documentos (títulos e resumos), identificamos que apenas 815 trabalhos traduziam a pesquisa em educação do campo. A maioria dos estudos relacionava o termo "educação do campo" a outros termos presentes na área da educação, tais como "educação física", "educação profissional", "educação indígena", dentre outros.

Cumpre esclarecer que a educação do campo se encontra como uma nova modalidade de educação no cenário educacional brasileiro, conforme orientam os seguintes documentos legais: a Resolução CNE/CEB n ${ }^{\circ}$ 4, de 13 de julho de 2010, que define as diretrizes curriculares nacionais gerais para a educação básica; a Resolução CNE/CEB no 1, de 03 de abril de 2002, que estabelece as diretrizes operacionais para a educação básica das escolas do campo; o Decreto $n^{\circ} 7.352$, de 04 de novembro de 2010, que infere sobre a política nacional de educação do campo e o Programa Nacional de Educação na Reforma Agrária - PRONERA.

\footnotetext{
${ }^{1}$ A Região Nordeste tem o total de 29 cursos de Pós-graduação em Educação cadastrados na Coordenação de Aperfeiçoamento de Pessoal de Nível Superior - CAPES, porém, desse valor, temos apenas 18 cursos reconhecidos. Os demais se encontram em fase de reconhecimento, aguardando a homologação do Conselho Nacional de Educação - CNE. No estudo, reportamo-nos apenas aos Cursos reconhecidos e destacados no site da CAPES, no total de 18 Programas de Pós-Graduação em Educação.

${ }^{2}$ Atentamos ainda, ao banco de dados do Scientific Eletronic Library Online - SCIELO e a base de dados da SCOPUS, galgando encontrar estudos a respeito do estado da arte sobre a pesquisa em educação do campo. Na busca, encontramos um estudo que se reporta ao estado da arte na Pesquisa em Educação acerca da Educação do Campo, nominada no período de Educação Rural, com o recorte de tempo de 1981 a 1996. O estudo realizado abarcava exclusivamente as investigações publicadas na Associação Nacional de Pós-graduação e Pesquisa em Educação - ANPED, sendo publicado em 2004. Clarificamos que como palavras-chave, para a busca da temática, utilizamos apenas o termo "educação do campo".
} 
Surgindo com essa nominação no ano de 1998, a partir da I Conferência Nacional "Por uma Educação Básica do Campo", essa modalidade educativa vem conseguindo, em articulação com movimentos sociais, sindicais e pastorais, legitimar o direito de uma educação específica para homens e mulheres que vivem do/no campo, permitindo sua inclusão social no bojo societal de nosso país (MEDEIROS, 2013).

O recorte temporal (1998 - 2015) deu-se tendo como justificativa o ano em que teve como marco o início dessa modalidade educacional brasileira, mesmo sabendo que sua institucionalização na legislação nacional tenha se concretizado apenas posteriormente, no ano de 2002, com a criação das diretrizes operacionais para educação básica das escolas do campo.

Esclarecemos, nesse momento, que a educação do campo tem um histórico antecedente ao período indicado nesse texto sobre sua criação como movimento educativo brasileiro (1998). Sabemos que a nominação atual representa um esforço coletivo de lutas, reivindicações e conquistas de educadores e educadoras do campo articulados aos movimentos sociais do campo. De tal modo, reconhecemos os diferentes termos que também se unificam ao atual, em virtude de suas contribuições para efetivação e sua materialização, tais como: educação rural, educação campesina, educação rurícola, dentre outros, bem como os diversos trabalhos de pesquisadores que foram construídos anteriormente, no contexto da educação para os povos do campo.

Destacamos que, no ano de 1998, foram traçadas políticas públicas, ações e atividades que culminaram na efetivação da educação do campo, no cenário educacional. A exemplo, pautamos o Curso de Pedagogia, do Projeto Pedagogia da Terra, primeiro curso de formação de professores do campo e a I Conferência Nacional "Por uma Educação Básica do Campo", em Luziânia - GO, em agosto do referido ano, que batiza a educação do campo até então nominada de educação rural, do mesmo modo, principia o debate sobre seus fundamentos e pressupostos, forjando nexos e diálogos dos movimentos sociais e sindicais do campo com instâncias estatais.

Assim, devido a essa configuração, pensamos em fazer um "balanço de conhecimentos" acumulados sobre a educação do campo do período de 1998, ano em que se efetivam ações que demarcam essa modalidade educativa brasileira no cenário nacional, até o momento atual, ano de 2015, validando as publicações de teses e dissertações de programas de pós-graduação em educação da Região Nordeste.

A análise do material encontrado e dialogado no texto proposita explicitar as temáticas recorrentes nas pesquisas, as tendências teóricas e as questões relacionadas aos aspectos metodológicos adotados nas investigações, dadas as necessidades de entender parte da produção científica construída na/pela pós-graduação em educação da região Nordeste sobre a temática.

Posto isso, dividimos o texto apresentando em três momentos: no inicial, traçamos breves considerações sobre a educação do campo no país, com vista ao entendimento do leitor sobre o tema; o segundo momento apresenta os caminhos metodológicos adotados na pesquisa para a concretização da investigação, aqui nominada de estado da arte; no terceiro momento, discorremos sobre os dados, os quais elucidam a pesquisa em educação do campo na pós-graduação em educação, na Região Nordeste.

\section{2 | AFINAL, O QUE É EDUCAÇÃO DO CAMPO?}

Dialogar sobre a educação do campo é uma tarefa que demanda um esforço analítico, pois ela se constitui na diversidade de múltiplos sujeitos que vivem e se fazem como humanos nos espaços rurais (ARROYO; CALDART; MOLINA, 2008).

Dessa forma, para iniciar o diálogo, chamamos atenção às mudanças no cenário educacional do país na década de 1990, oriundas das recomendações da Lei de Diretrizes e Bases da Educação 
Nacional (LDB), $n^{\circ}$ 9.394, de 20 de dezembro de 1996, a partir das quais os movimentos sociais do campo impeliram o governo a debater com eles uma proposta de educação do campo e não para o campo, uma vez que, até o momento, havia se refletido oficialmente a educação para as populações rurícolas de acordo com um modelo urbanocêntrico ${ }^{3}$ de educação (ARROYO; CALDART; MOLINA, 2008; OLIVEIRA, 2013).

Nesse caminho, concebemos a Educação do Campo como algo recente no cenário da educação brasileira. Conforme Caldart (2012, p. 257), a educação campesina

\begin{abstract}
[...] nomeia um fenômeno educacional na realidade brasileira, protagonizado pelos movimentos sociais e suas organizações. [...] objetivo e sujeitos remetem às questões do trabalho, da cultura e das lutas sociais camponesas, entre projetos de campo e entre lógicas da agricultura que têm implicações no projeto de país e de sociedade e nas concepções de políticas públicas, de educação e formação humana.
\end{abstract}

A partir do exposto, compreendemos que a educação do campo emerge dos movimentos sociais na luta pela terra e pela reforma agrária, na luta por uma educação construída pelos sujeitos do campo e não produzida exterior a eles. Luta antiga das populações campestres pelo direito a viver com/na terra e a uma educação específica voltada às necessidades dos povos rurais (STÉDILE, 2002; OLIVEIRA, 2013).

Todavia, fechar um conceito de educação do campo, nesse texto, traz a nós o risco de minimizá-la, de torná-la reducionista. A educação do campo se contrapõe às tendências que hoje se mostram marcantes da concepção de educação rural, presente no largo caminho histórico da educação para as populações campesinas, que inferioriza o camponês e que ajuda a construção de um ideal de homem do campo, como o caipira, o analfabeto, o sem terra, o marginal.

Com vista a esclarecer o entendimento sobre a educação do campo e, nesse ínterim, algumas das tendências marcantes da concepção de educação rural, apresentamos um quadro-síntese, na perspectiva de Molina (2006), Caldart (2012), Fernandes (2006), Oliveira (2013) e Medeiros e Aguiar (2015) que traduz os escritos anteriormente acerca da educação campesina e suas características e das tendências marcantes da educação rural.

\title{
Quadro 1 - Características predominantes da Educação do Campo x Educação Rural
}

\begin{tabular}{|ll|}
\hline Educação do Campo & Educação Rural \\
\hline Território do campesinato e da agricultura familiar & Território do agronegócio \\
\hline $\begin{array}{l}\text { Projeto de educação sintonizado e ancorado à reali- } \\
\text { dade do campo }\end{array}$ & Modelo da educação urbana \\
\hline Proposta de educação interdisciplinar & Educação descontextualizada e fragmentada \\
\hline $\begin{array}{l}\text { Escola interativa com a comunidade e seu desenvolvi- } \\
\text { mento social, cultural, político e econômico }\end{array}$ & $\begin{array}{l}\text { Escola isolada em relação aos problemas da comuni- } \\
\text { dade }\end{array}$ \\
\hline $\begin{array}{l}\text { Perspectiva de temporalidades diversas e de multi- } \\
\text { dades na educação }\end{array}$ & Perspectiva da multissérie na educação \\
\hline $\begin{array}{l}\text { Formação de professores focada na luta social dos } \\
\text { povos do campo }\end{array}$ & Formação de Professores sob a ótica do capital \\
\hline
\end{tabular}

Fonte: Molina (2006), Caldart (2012), Fernandes (2006), Oliveira (2013), Medeiros e Aguiar (2015).

\footnotetext{
${ }^{3} \mathrm{O}$ modelo urbanocêntrico de educação pode ser entendido como aquele que é produzido por profissionais da educação, com foco no desenvolvimento das grandes cidades, do agronegócio e do êxodo rural e posteriormente é levado ao campo. Esse modelo descredita o campo e seus sujeitos, apresentando-o como espaço de subdesenvolvimento e de marginalização (ARROYO; CALDART; MOLINA, 2008).
} 
O quadro aponta as dimensões da educação do campo, materializa, em linhas gerais, o que ela é, ou seja, ela decorre da ação dos movimentos sociais do campo no pleito pela terra, articulando o campo à vida educacional de seus povos.

É com vista nessa concepção de educação que os movimentos sociais e os povos do campo conseguiram a aprovação das diretrizes operacionais para a educação básica das escolas do campo, no ano de 2002.

Apesar de a LDB n 9.394/96 apontar, no art.28, considerações para a normatização da educação do campo, propondo adequação das escolas localizadas em áreas rurais à vida nos espaços campestres, somente após as diretrizes operacionais da educação básica do campo (2002) é que se firma, em linhas explicativas, a exigência da efetivação do direito à educação dos povos rurícolas.

Salientamos também que o Decreto $n^{0} 7.352 / 10$ reafirma as especificidades da escola do campo, de seus povos, os princípios da educação campesina, as perspectivas para a formação de professores do campo, dentre outras. Acrescente-se a isso a inclusão das discussões sobre formação docente para a Educação do/no Campo, na Resolução CNE/CP $n^{\circ} 2$, de $1^{\circ}$ de julho de 2015, que "Define as Diretrizes Curriculares Nacionais para a formação inicial em nível superior (cursos de licenciatura, cursos de formação pedagógica para graduados e cursos de segunda licenciatura) e para a formação continuada" (BRASIL, 2015).

Mesmo com esse cenário favorável à construção da educação do campo, não podemos afirmar que isso garante a sua concretização. Ela, sendo em si um movimento educacional no país, luta incessantemente por sua efetivação nos espaços campestres. Os povos do campo, de 1998 até o ano de 2015, conseguiram, nos embates e reivindicações com o Estado, muitas conquistas, dentre elas, estão: a obtenção de marcos legais e de programas educacionais destinados ao campo e criados em parcerias com seus sujeitos, a inserção do tema na agenda nacional das universidades brasileiras e a visibilidade da realidade campesina por parte de nossa sociedade. É nessa direção que continuamos a luta pelo direito de ser do campo e de nele construir uma educação que atente e atenda ao que vivemos, ao nosso campo (MOLINA; HAGE, 2015).

\section{3 | CAMINHOS METODOLÓGICOS DO ESTUDO: a construção do estado da arte}

O estado da arte exposto nesse texto proposita mapear e discutir a produção científica desenvolvida sobre a educação do campo, na pesquisa da pós-graduação em educação da Região Nordeste. Entre outros aspectos, estamos interessados em evidenciar as temáticas das investigações, as tendências teóricas e os aportes metodológicos dos estudos.

Para tanto, fizemos a análise de 105 dissertações e de 32 teses em 18 Programas de Pós-Graduação em Educação de universidades públicas e privadas da Região Nordeste (10 universidades federais, 05 universidades estaduais e 01 universidade privada) 4 .

Considerando esses elementos, traçamos, para a construção, análise e interpretação dos dados, a seguinte sequência metodológica descrita a seguir.

\footnotetext{
${ }^{4}$ No ano de 2013, foram registrados e avaliados 159 Programas de Pós-Graduação em Educação no país, conforme a Diretoria de Avaliação da CAPES 2013. Desse total, há 29 programas de pós-graduação em educação na Região Nordeste, contudo, apenas 18 programas têm seu reconhecimento homologado pelo Conselho Nacional de Educação - CNE, coexistindo em 10 universidades federais, em 05 universidades estaduais e em 01 universidade privada. Dos 18 Programas de Pós-Graduação em Educação da Região Nordeste, referenciados nesse estudo, 08 cursos ofertam a pós-graduação Stricto Sensu em nível de Mestrado (06 na modalidade acadêmica e 02 na modalidade profissional) e 10 cursos ofertam tanto em nível de Mestrado Acadêmico, como em nível de Doutorado.
} 
No primeiro momento, realizamos o levantamento e selecionamos as teses e as dissertações nos Bancos de Dados das Bibliotecas Digitais e nos sites dos Programas de Pós-Graduação em Educação, da Região Nordeste.

Esses procedimentos possibilitaram identificar o movimento da pesquisa sobre educação do campo, nos programas de Pós-Graduação em Educação, de cada Estado da Região Nordeste, no sentido de perceber onde se polarizam as investigações. Ao visitar os sites dos referidos Programas, concebemos também suas linhas de investigação, seus grupos de pesquisa e estudo.

Alertamos que dos 18 Programas visitados, 02 não disponibilizam acervo digitalizado aberto à consulta. Para conseguirmos o material, recorremos às listas de teses e dissertações apresentadas pelos Programas em suas páginas na internet, considerando o recorte temporal (1998 - 2015). A partir delas, buscamos os documentos diretamente com as coordenações dos Cursos.

No segundo momento, fizemos a leitura dos títulos e dos resumos das teses e das dissertações. A leitura dos títulos e dos resumos das teses e dissertações permitiu conceber as principais temáticas que se encontram nas pesquisas. Após realizar esse procedimento com os documentos, organizamos os trabalhos em 09 categorias, as quais agrupam as temáticas investigadas na pesquisa sobre educação do campo, a saber: Políticas Educacionais, Formação de Professores, Movimentos Sociais, Educação Profissional, Educação Rural ${ }^{5}$, Currículo, Escolas do Campo, Juventudes no Campo e Outros Temas.

Lembramos que as categorias surgiram após toda a leitura do material, enfatizamos que não construímos categorias antes de finalizar a leitura dos documentos. As categorias emergiram a partir de trabalhos com temáticas que representam $05 \%$ de toda a produção científica (teses e dissertações).

Encontramos alguns estudos que não foram relacionados dentro das categorias elucidadas. Esses trabalhos foram acoplados a uma categoria nominada de "Outros Temas", a que agrupa as pesquisas que não representam o percentual considerado (05\%) para classificação em uma das categorias existentes.

No terceiro momento, debruçamo-nos na leitura de capítulos teórico-metodológicos e da revisão da literatura das teses e das dissertações. Nessa etapa, adentramos nas tendências teóricas presentes nos textos e nos aspectos metodológicos que se fiaram nas investigações. Também organizamos os dados após finalizar as leituras.

No quarto momento, concretizamos a análise quantitativa dos trabalhos. Nesse período, sistematizamos os dados referentes às temáticas pesquisadas, às tendências teóricas e aos aspectos metodológicos, em gráficos, quadros e tabelas para posteriormente concretizarmos a análise qualitativa do material encontrado.

Por fim, no quinto momento, realizamos a análise qualitativa dos dados. Nessa fase, interpretamos os documentos agrupados a partir da sistematização dos dados apresentados nos gráficos, nos quadros e nas tabelas, considerando os sentidos que os dados inferem ao objetivo do estudo: evidenciar a produção científica sobre educação do campo, na pesquisa em educação, da Pós-Graduação em Educação da Região Nordeste.

\footnotetext{
${ }^{5}$ Abrimos um espaço para pontificar que os estudos sobre Educação Rural, quase todos, se associam à história da educação. Isso é justificado porque a nomenclatura Educação Rural predominou até o final da década de 1990, momento em que a educação do campo ganha circunferência no cenário educacional do Brasil. Todos os estudos categorizados nessa dimensão possuem o termo e se perspectivam nesse caminho. Consideramos, a partir do exposto, que os estudos apresentados nesse texto, na categoria Educação Rural, podem também ser pontuados aos estudos que se vinculam à história da educação para os povos do campo. Quando associamos os estudos à Educação Rural, não os interligamos com as tendências marcantes da educação rural, as quais descaracterizam o campo e seus atores/sujeitos.
} 
Com base no exposto, acentuamos que esse foi o caminho metodológico vivenciado no estudo e, mesmo sabendo que os resultados representam um número pequeno do que se vive e se produz sobre educação do campo na Pós-Graduação em Educação do país, o estudo é de suma importância para concebermos a educação campesina no palco da pesquisa em educação, desse espaço geográfico (Região Nordeste).

\section{4 | A PRODUÇÃO CIENTÍFICA EM EDUCAÇÃO DO CAMPO NA PÓS-GRADUAÇÃO EM EDU- CAÇÃO DA REGIÃO NORDESTE: um mapa}

De 1998 a 2015, foram identificadas 105 dissertações e 32 teses, totalizando 137 trabalhos na Pós-Graduação em Educação da Região Nordeste, concernentes à educação do campo. É notório que esse número é significativo, principalmente devido ao tempo de consolidação da educação do campo (ano de 1998), como uma modalidade educativa da educação nacional.

Como primeiro dado para análise no estudo, apresentamos um gráfico que explana em números a quantidade de investigações desenvolvidas sobre educação do campo, na Pós-Graduação em Educação, segundo os Estados da Região Nordeste.

Gráfico 1 - Distribuição das teses e dissertações por Estado na Região Nordeste

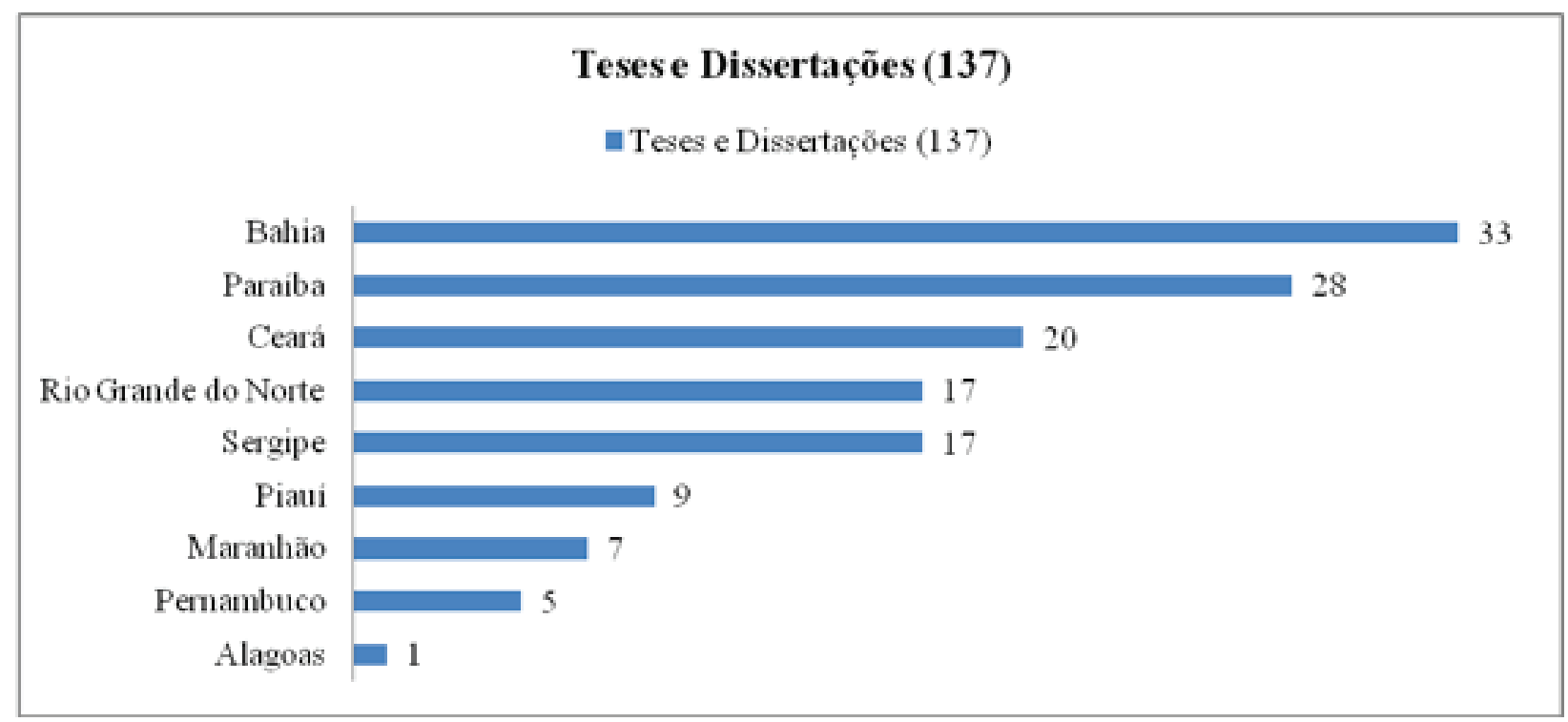

Fonte: Dados dos pesquisadores

É visível, a partir dos dados, que o Estado da Bahia é o que concentra o maior número de teses e dissertações, seguido da Paraíba e do Ceará. Em uma análise explicativa, os três Estados desenvolveram quase $60 \%$ dos estudos que versam acerca da educação do campo na Pós-Graduação em Educação da Região Nordeste.

Como um elemento relevante da análise, destacamos que a Bahia é o Estado que possui o maior volume de dissertações (28), acompanhadas de 05 teses. A Paraíba, por conseguinte, se destaca apresentando 06 teses e 22 dissertações e o Ceará se penetra ao movimento dos estudos com 09 teses e 11 dissertações. 
Para entendimento sobre o quantitativo eloquente acerca das teses e dissertações nos três Estados (Bahia, Paraíba e Ceará), podemos validar as áreas de concentração, as linhas e os núcleos de investigação dos Programas de Pós-Graduação em Educação dos Estados citados, as quais tematizam a educação do campo, ou temas que se aproximam da discussão: educação popular, movimentos sociais, educação em contextos locais, dentre outros.

Nessa linha interpretativa, consideramos também como instrumento para diálogo os trabalhos desenvolvidos nos Estados de Alagoas, Pernambuco, Maranhão e Piauí, que juntos somam pouco mais de $15 \%$ das pesquisas. Nos quatro Estados, temos apenas 02 teses, ambas publicadas no Estado de Pernambuco e 20 dissertações.

Os Estados do Rio Grande do Norte e Sergipe possuem um quantitativo de investigações equivalente na pesquisa em educação do campo (17 trabalhos em cada Estado). No entanto, o Rio Grande do Norte se apresenta com um volume superior de teses (09) e com um número inferior de dissertações (08). No Estado do Sergipe foram desenvolvidas 15 dissertações e 02 teses.

Como forma de elucidar melhor a distribuição da produção científica em educação do campo na Pós-Graduação em Educação do entorno geográfico supracitado, organizamos os dados no quadro que segue, de acordo com as instituições em que as pesquisas foram realizadas, bem como a quantidade específica de teses e dissertações publicadas consoante com a educação do campo pelos programas pertencentes às universidades ${ }^{6}$.

Quadro 2 - Quantitativo de teses e dissertações por universidade

\begin{tabular}{|llll|}
\hline Universidades & Teses & Dissertações & $\mathbf{N}^{\mathbf{0}}$ de Trabalhos \\
\hline UFRN & 06 & 09 & 15 \\
\hline UERN & 00 & 02 & 02 \\
\hline UECE & 00 & 03 & 03 \\
\hline UFC & 09 & 08 & 17 \\
\hline UFPB & 06 & 20 & 26 \\
\hline UEPB & 00 & 02 & 02 \\
\hline UFPE & 02 & 02 & 04 \\
\hline UFRPE & 00 & 01 & 01 \\
\hline UFMA & 00 & 07 & 07 \\
\hline UFPI & 00 & 09 & 09 \\
\hline UFBA & 05 & 10 & 15 \\
\hline UNEB & 02 & 11 & 13 \\
\hline UEFS & 00 & 05 & 05 \\
\hline UFS & 02 & 14 & 16 \\
\hline UNIT - SE & 00 & 01 & 01 \\
\hline UFAL & 00 & 01 & 01 \\
\hline
\end{tabular}

Fonte: Dados dos pesquisadores.

\footnotetext{
${ }^{6}$ Esclarecemos que a Universidade Federal do Pernambuco possui dois programas de Pós-graduação em Educação: um na cidade de Recife e outro na cidade de Caruaru. Dos quatro trabalhos, três foram produzidos no programa localizado no município de Recife. Do mesmo modo, a Universidade Estadual do Ceará também possui dois programas de Pós-Graduação em Educação: um na cidade de Fortaleza e um intercampi nas cidades de Limoeiro do Norte e Quixadá. Dos três estudos, dois se realizaram no programa na cidade de Fortaleza.
} 
Das 137 teses e dissertações, 26 do total se localizam na Universidade Federal da Paraíba UFPB, a qual é considerada a instituição que mais contempla a produção em educação do campo na Pós-Graduação em Educação da Região Nordeste.

No que tange à universidade em que se concentra o maior número de teses, frisamos a Universidade Federal do Ceará - UFC, com 09 estudos, seguida da Universidade Federal do Rio Grande do Norte - UFRN, com 06 estudos.

As dissertações além de se centralizarem na Universidade Federal da Paraíba - UFPB (22), também se destacam na Universidade Federal de Sergipe - UFS (14). É relevante realçar que na esfera estadual, temos um número considerável de estudos dissertativos realizados na Universidade do Estado da Bahia - UNEB (11).

Dentro dessa conjuntura, chamam-nos atenção as poucas investigações concretizadas pelas demais universidades estaduais que totalizam 02 teses em toda a produção sobre educação do campo. Contudo, não podemos deixar de lembrar que dos 06 programas existentes nessas universidades, somente 02 possuem o stricto sensu em nível de doutorado (UNEB e UECE), existindo poucas pesquisas concluídas, como é o caso da Universidade Estadual do Ceará - UECE, que ainda se encontra no processo de formação de sua terceira turma, não tendo estudos finalizados de doutoramento.

O quadro expressa outro importante ponto para a reflexão concernente à presença de estudos sobre a temática nos 18 programas de Pós-Graduação em Educação da Região Nordeste analisados aqui. Mesmo sendo elucidativa a predominância de trabalhos em instituições que ofertam a Pós-Graduação em Educação há mais de vinte anos (UFPB, UFRN e UFC), há pesquisas realizadas em todos os cursos, igualmente naqueles que tiveram sua criação recentemente, entre os anos de 2010 a 2012, como é o caso dos cursos de Pós-Graduação em Educação da Universidade Estadual de Feira de Santa - UEFS (05), da Universidade do Estado do Rio Grande do Norte - UERN (02), da Universidade Estadual da Paraíba - UEPB (02) e da Universidade de Tiradentes - UNIT - SE (01).

Esse dado ilustra o interesse por pesquisadores acerca da educação do campo, no contexto da pesquisa em educação da Região Nordeste, porém, de acordo com Damasceno e Beserra (2004), tal interesse não nasce da clarividência ou excessiva sensibilidade dos estudiosos do tema, mas das próprias circunstâncias da realidade em estudo (crescimento de ações e atividades direcionadas ao campo, advindos das lutas dos movimentos sociais).

Em outras palavras, dizemos que são os próprios sujeitos do campo que, por meio de sua organização política, tornam-se suficientemente visíveis para chamarem sobre si a atenção dos estudiosos a respeito de que o campo e sua educação estão vivos e em movimento.

\subsection{Temáticas Investigadas: o que se pesquisa sobre educação do campo na Região Nordeste?}

Os temas encontrados nas pesquisas da Pós-Graduação em Educação da Região Nordeste, considerando o recorte de 1998 a 2015, são tratados de acordo com a categorização que orientou as 137 investigações. A seguir, apontamos detalhadamente as principais temáticas no conjunto das produções científicas. 
Gráfico 2 - Temáticas investigadas sobre educação do campo

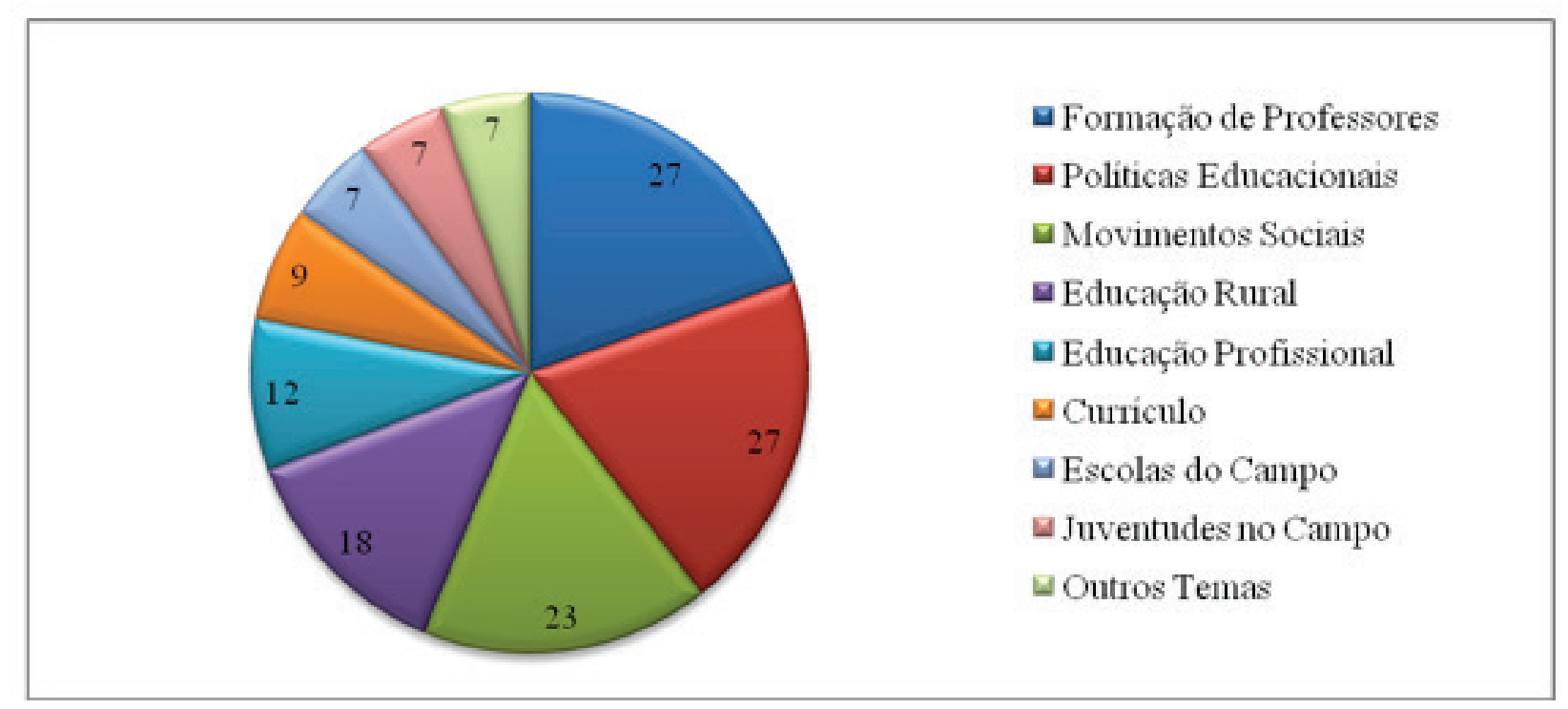

Fonte: Dados dos pesquisadores.

Na frente das temáticas investigadas aparecem os estudos sobre a Formação de Professores e as Políticas Educacionais com o percentual de 27 trabalhos (20\%), cada categoria, representando juntas $40 \%$ dos temas pesquisados.

Com um fluxo massivo nas investigações, estudos sobre os Movimentos Sociais, num total de 23 produções (17\%), a Educação Rural, 18 investigações (13\%), a Educação Profissional, 12 pesquisas (9\%) e o Currículo, 09 publicações (07\%), também merecem menção dentro do quadro inventariado sobre as temáticas investigadas.

Com menor expressão encontramos trabalhos a respeito das Escolas do Campo, 07 produções (05\%) e das Juventudes no Campo, 07 pesquisas (05\%). Acrescentamos ainda um valor não desprezível de estudos, num total de 07 trabalhos (05\%), que trazem temas variados.

Na categoria Formação de Professores, estão presentes 08 teses e 19 dissertações. As discussões atestam o seguinte: a formação inicial (14) e continuada (04), a identidade docente (03), a implantação de políticas de formação de professores nas universidades (02), a profissionalização (02), os saberes docentes (01) e a formação de professoras militantes (01).

Com referência à análise dos dados, os estudos que realçam a formação inicial (14) se reportam, quase que exclusivamente, à formação do professor no Curso de Pedagogia, do Projeto Pedagogia da Terra. Entretanto, as temáticas investigam a formação inicial em diferentes perspectivas: o estágio supervisionado e suas contribuições à formação (01), a pedagogia da alternância (02), os princípios e os fundamentos políticos dos movimentos sociais do campo na formação docente (01), a formação inicial com ênfase para a educação de jovens e adultos (01) e para a educação em classes multisseriadas (01), as contribuições de ações e componentes curriculares da formação concretizados nas comunidades do campo (01), as percepções de discentes sobre a formação do professor do campo (01), as histórias de vida de graduandos articuladas aos processos formativos vivenciados na universidade (02), a relação teórico-prática vivenciada no curso acerca de seus fundamentos (02). Há um (01) estudo sobre a formação inicial na Licenciatura em educação do campo, nova modalidade de formação de professores do campo e outro sobre o curso de formação de alfabetizadores para a formação de jovens e adultos. 
A formação continuada (04) apresenta pesquisas que validam a formação de professores do campo que já exercem o magistério, tendo como norte experiências de ações, programas e atividades direcionados ao professor do campo, com realce na formação em serviço (01), na avaliação de trajetórias de formação (01) e na formação pedagógica (02).

Os trabalhos mapeados atinentes à identidade docente (03) conduzem-se para o tornar-se professor do campo (01), o perfil do educador e da educadora do campo (01) e as concepções dos graduandos sobre a identidade docente do professor do campo (01).

As investigações referentes à implantação de políticas de formação de professores do campo, em universidades (02), agudizam o olhar para as primeiras experiências de formação de professores, via PRONERA, do curso de Pedagogia (01) e do curso de Ciências Agrárias (01) desenvolvidos no Estado da Paraíba, em parceria com os movimentos sociais.

Os estudos que tematizam os saberes docentes (01), a profissionalização (02) e a formação das professoras militantes (01) auferem sobre os saberes da experiência, a precarização da profissão professor em escolas do campo e a formação da professora militante que, para além de docente, atua como agente social nas comunidades do campo.

As pesquisas correspondentes às Políticas Educacionais ( 05 teses e 22 dissertações) atribuem destaque às políticas para a educação básica, em especial à educação infantil e ao ensino fundamental, como os Programas Escola Ativa (12) ${ }^{7}$, Saberes da Terra (01) e o Projovem Campo (01).

Estudos sobre o Programa Nacional de Educação da Reforma Agrária - PRONERA (09) também são encontrados. As pesquisas palmilham na direção de ações oriundas do programa e sua consolidação em Estados (Paraíba, Sergipe e Bahia) e municípios da Região Nordeste.

$\mathrm{Na}$ categoria em discussão (Políticas Educacionais), surgem estudos sobre as políticas de formação de professores (04), porém, diferentemente das investigações que apresentaram essa característica, na categoria Formação de Professores, o foco das investigações diz respeito às políticas de um modo geral e não à formação docente.

As investigações abordando os Movimentos Sociais (08 teses e 15 dissertações) se preocupam com a relação trabalho e educação (07). Além desse ponto, há estudos que se deslocam para as práticas educativas vivenciadas no Movimento dos Trabalhadores Rurais Sem Terra MST (06), no Movimento dos Pequenos Agricultores - MPA (01), no Movimento dos Pescadores Artesanais (01) e no Movimento dos Atingidos por Barragens - MAB (01).

Em uma mesma esteira, há pesquisas que se remontam para a qualidade da educação presente em áreas de assentamentos e acampamentos exercidos a partir da luta dos movimentos sociais do campo (03), a formação do militante nos espaços de luta pela reforma agrária (01), as contribuições do MST para a educação do campo, no Estado da Bahia (01), as ligas camponesas na Paraíba (02).

No âmago das pesquisas que enunciam a Educação Rural (01 tese e 17 dissertações), existem investigações sobre a criação das escolas normais rurais do Ceará (02) e da Bahia (01), as práticas educativas de professoras de escolas rurais (03), a formação do professor ruralista no período de 1934 a 1974 (01), as escolas elementares rurais (03), a educação rural na Paraíba (02) e no Rio Grande do Norte (01), a identidade do aluno ruralista (01), as memórias e experiências de professoras sergipanas (01), a educação rural na ditadura militar (01), as classes multisseriadas no sertão paraibano (01) e piauiense (01).

\footnotetext{
${ }^{7}$ Apesar das inúmeras críticas advindas do coletivo campesino ao Programa Escola Ativa, alocamos as publicações que caminham sobre o mesmo na categoria política educacional. Não pretendemos apresentar nenhuma descrição sobre sua natureza e seus fundamentos. Consideramos que o Programa se caracteriza como uma política educacional, pois advém de um terreno institucionalizado.
} 
A Educação Profissional, por seguinte, cobriu um total de 05 teses e 07 dissertações, com estudos que retratam a educação de camponeses em escolas famílias agrícolas (03) e as práticas educativas desenvolvidas em comunidades, via alternância (01), as atividades extensionistas em associações e cooperativas agrícolas (03), as contribuições da formação nas casas familiares rurais para jovens do campo (01), a alternância na formação de jovens e adultos nas escolas técnicas agrícolas no Maranhão (01), a formação de jovens agricultores do Estado da Bahia para o trabalho com a agricultura familiar agroecológica (01), a formação do técnico agropecuário no Instituto Federal de Educação, Ciência e Tecnologia Baiano (01) e a educação profissional de homens e mulheres do campo, em cursos do Programa Nacional de Acesso ao Ensino Técnico e Emprego - PRONATEC (01).

No campo do Currículo (01 tese e 08 dissertações), encontram-se investigações que se deslindam a respeito do currículo de cursos de formação de professores do campo (04), da cultura do campo nas práticas curriculares em escolas do campo (01), da construção do currículo de escolas do campo com a participação dos movimentos sociais do campo (02), da contextualização de conhecimentos e saberes escolares no processo de reorientação curricular, em escolas do campo ligadas ao MST (01) e ao movimento negro no Estado da Bahia (01).

As pesquisas que percorrem pelas Escolas do Campo (01 tese e 06 dissertações) patenteiam investigações sobre as práticas pedagógicas em escolas do campo (03), o projeto pedagógico da escola do MST (01), a organização pedagógica e escolar em instituições campestres (01) e as tecnologias da informação e da comunicação (02).

As produções em relação às Juventudes no Campo (02 teses e 05 dissertações) descrevem pesquisas quanto à identidade de jovens do campo (02), às influências da cultura digital na construção da identidade juvenil campesina (01), às tecnologias como recurso de socialização de saberes entre jovens do campo (01), à violência no campo (01), aos projetos de vida e trabalho da juventude militante do MST (01) e à mística como prática político-social de afirmação da identidade juvenil rurícola (01).

Na última categoria, Outros Temas (05 teses e 02 dissertações), falamos de trabalhos que não se vinculam às temáticas apreciadas previamente, não obstante, comungam diretamente com a educação do campo, relacionando-se ao campo e aos seus sujeitos.

Deparamo-nos com temáticas investigativas em relação à educação ambiental em áreas de assentamento oriundos da reforma agrária (03), à educação matemática em comunidades do campo ditas tradicionais (01), ao ensino de ciências com discentes do ensino médio, em escolas rurais (01), ao Estado da Arte da educação infantil na educação do campo e na educação rural no Brasil - 2002 a 2012 (01) e ao ensino de história em classes multisseriadas (01).

Torna-se importante discorrer, com parâmetro na análise conjunta do material, que as teses e dissertações apontam uma educação do campo que trilha com as políticas educacionais, com programas e projetos voltados às populações rurais, com a formação docente, com os movimentos sociais, com a educação popular. Os temas em cena nas investigações são atuantes em um mundo-campo real, postos à universidade.

\subsection{Das tendências teóricas: quais referências existentes?}

Na apreciação das 137 produções, pensamos em anunciar os autores citados seguindo as categorias estabelecidas nas temáticas investigadas. Contudo, como estamos inseridos no terreno epistemológico da pesquisa em educação sobre educação do campo, a seleção das tendências teóricas encontradas foi sistematizada a partir da relação e discussão dos aportes teóricos dentro do campo conceitual e científico da educação do campo. 
Os autores e obras referenciadas nas produções não traduzem simplesmente seus elos com as temáticas, presentes nas investigações. Sua vinculação diz da coerência dos escritos e estudos na educação do campo.

Tabela 1 - Tendências teóricas na pesquisa sobre educação do campo

\begin{tabular}{|c|c|}
\hline Principais Autores & Principais Referências \\
\hline Paulo Freire & $\begin{array}{l}\text { - Pedagogia da Autonomia } \\
\text { - Pedagogia do Oprimido }\end{array}$ \\
\hline Roseli Salete Caldart & $\begin{array}{l}\text { - Pedagogia do Movimento Sem Terra } \\
\text { - Pedagogia do Movimento }\end{array}$ \\
\hline Mônica Castagna Molina & $\begin{array}{l}\text { - Educação do Campo e Pesquisa: questões } \\
\text { para reflexões }\end{array}$ \\
\hline Miguel Arroyo & $\begin{array}{l}\text { - Por uma educação do campo } \\
\text { - A Educação Básica e o Movimento Social do } \\
\text { Campo }\end{array}$ \\
\hline Maria da Glória Gohn & $\begin{array}{l}\text { - Movimentos Sociais e Educação } \\
\text { - Teoria dos Movimentos Sociais }\end{array}$ \\
\hline Bernardo Mançano Fernandes & $\begin{array}{l}\text { - Questão Agrária, Pesquisa e MST } \\
\text { - A Formação do MST no Brasil }\end{array}$ \\
\hline João Pedro Stédile & $\begin{array}{l}\text { - A Questão Agrária no Brasil } \\
\text { - Brava Gente }\end{array}$ \\
\hline Carlos Rodrigues Brandão & $\begin{array}{l}\text { - O que é Educação } \\
\text { - Educação Popular na Escola Cidadã }\end{array}$ \\
\hline
\end{tabular}

No conjunto de autores e obras citadas nas produções, Paulo Freire, com suas publicações, se sobressai como principal tendência no campo da educação do campo. A grande parte dos estudos apresenta o autor pernambucano como a referência central nos trabalhos. As obras Pedagogia da Autonomia e Pedagogia do Oprimido ganham destaque no rol científico. O autor é aludido principalmente nos estudos sobre a Formação de Professores e a Educação Rural, não sendo divergente nos trabalhos sobre as Escolas do Campo e as Juventudes no Campo.

É importante citar que inúmeros outros autores também são mencionados, nas categorias citadas no parágrafo anterior, embora sejam em menor peso, como, por exemplo, Bernard Charlot (2005), Bernadete Gatti (2000), Dermeval Saviani (2007), Eduardo Wanderley (2010), dentre outros.

Roseli Salete Caldart, Mônica Castagna Molina e Miguel Arroyo são aportes teóricos com grande força existentes nas publicações. Nos 137 estudos, é unânime a presença dos três autores. No contorno das produções, estão obras basilares sobre educação do campo: Pedagogia do Movimento Sem Terra, Por uma Educação do Campo, A Educação Básica e o Movimento Social do Campo e Pedagogia do Movimento.

A ênfase nos três autores aparece nos estudos que se desenham acerca das Políticas Educacionais, do Currículo, da Formação de Professores e principalmente da Educação Profissional. 
Maria da Gloria Gohn, Bernardo Mançano Fernandes, João Pedro Stédile e Carlos Rodrigues Brandão são aportes valiosos nos estudos a respeito dos Movimentos Sociais. As obras Movimentos Sociais e Educação, O que é Educação, A Formação do MST e Brava Gente também povoam a grande parte das investigações que abordam a temática.

$\mathrm{Na}$ interpretação dos documentos, percebemos alguns pontos que devem ser mencionados aqui: o primeiro diz da não utilização de artigos, teses, dissertações e outros gêneros textuais científicos nas discussões. Os livros são sem dúvida a principal fonte de referência. O segundo ponto é a pouca presença da literatura internacional que dialogue com os aportes teóricos da educação do campo e, por último, destacamos a tímida presença de referências sobre a educação do campo.

Por ser uma temática nova no cenário acadêmico, também são poucos os pesquisadores que têm conseguido apresentar suas publicações e dar suporte epistêmico à comunidade que pesquisa sobre/na educação do campo. As produções apresentadas recorrem a autores que são "consagrados" em outras temáticas. Como exemplo, temos o Carlos Rodrigues Brandão (Educação Popular) e a Maria da Gloria Gohn (Movimentos Sociais e Educação Não Formal).

\subsection{Aspectos Metodológicos da Pesquisa em Educação na Educação do Campo: abor- dagens, procedimentos, sujeitos e contextos presentes}

Na última dimensão analisada nos documentos, penetramos nos aspectos metodológicos dos estudos. Destacamos que nesse ponto não objetivamos percorrer aguçadamente nas teses e nas dissertações, logo o nosso interesse é o de perceber o movimento metodológico dos pesquisadores e de suas produções.

A tentativa analítica experienciada, nesse contorno, foi de identificar os tipos de pesquisa, as abordagens utilizadas, os principais métodos e procedimentos de coleta de dados, e, mais que isso, os sujeitos e contextos em que as investigações se fiaram.

Sobrelevamos que na leitura dos documentos sentimos dificuldades em conceber alguns dos caminhos e procedimentos metodológicos exercidos nas produções. Muitas pesquisas não pontuam, textualmente, o tipo de investigação a que se propõe. Algumas delas relacionam os tipos de estudo com as abordagens utilizadas. As técnicas de coleta de dados são comumente identificadas como sendo a própria metodologia, os sujeitos da pesquisa são confundidos com os lócus de investigação. Tudo isso dificultou nossa análise e compreensão a respeito das produções.

No concernente aos tipos de pesquisa, dividimos as produções em dois tipos: empíricas e teóricas, com base nos escritos de Minayo (2007). Nessa trilha, das 137 investigações, 128 deixam entendimentos do carácter empírico da investigação, ponderando nos procedimentos percorridos. São investigações que se realizam nos contextos das escolas e salas de aula no campo, em áreas de assentamentos, acampamentos e comunidades rurais, nas universidades e nos cursos de formação de professores, nas sedes dos sindicatos e movimentos sociais, em associações e espaços não formais de ensino, nas escolas técnicas agrícolas e em centros educativos que acolhem jovens e adultos do campo.

As pesquisas que são classificadas como teóricas (09) se fundamentam na análise "exaustiva" de documentos, caracterizando-se assim como documental e bibliográfica. Esse quadro evidencia a preferência dos pesquisadores por estudos que adentram no universo real dos povos do campo.

As abordagens de pesquisas encontradas seguem, preferencialmente, o cunho qualitativo de investigação (135 aproximadamente). Sobre isso, temos apenas 01 estudo que diz adotar a abordagem quantitativa e 01 estudo que pontifica a abordagem quanti-qualitativa como utilizada na pesquisa (ambos os estudos são dissertativos). 
As metodologias e os métodos de pesquisa, apontados nas investigações, aqui nominadas de empíricas, foram intitulados pelos pesquisadores como estudo de caso (32), pesquisa-ação (08), pesquisa exploratória (12), investigação-formação (05), história oral (07), histórias de vida (09), pesquisa colaborativa (04), pesquisa etnográfica (07), pesquisa participante (04), análise do discurso (03), pesquisa historiográfica (08) e pesquisa histórico-documental (01). Rememoramos que em 28 produções não foi possível definir os métodos e também caracterizar a metodologia sistematizada, pois os estudos encenam, no texto, caminhos que não conseguimos interpretar. Esse ponto é visível, principalmente nos estudos dissertativos.

Dentre as técnicas/procedimentos de coleta de dados mais referenciados nas produções, sobressaem-se as entrevistas, os questionários, as observações, os diários e as sessões reflexivas, os grupos focais, a análise de conteúdo, as narrativas de formação, as histórias de vida, os memoriais, dentre outros. Nesse enredo, encontramos pesquisas que se pautam em mais de uma técnica de coleta ou em vários procedimentos metodológicos, por isso, não quantificamos aqui o total específico de técnicas e procedimentos adotados nas investigações.

No que convém aos sujeitos das investigações também encontramos um terreno plural. Os participantes são alunos, professores, coordenadores e gestores de escolas do campo, ou de escolas que agregam ao coletivo camponês, isto é, que tem como público principal os sujeitos dos espaços rurais. Homens e mulheres, militantes e atuantes em movimentos sociais do campo são os protagonistas que exercem as investigações com seus ditos e escritos.

Em relação aos contextos, nos quais se concretizam os estudos, evocamos que as pesquisas partem de um campo-sertão, para um campo-educação. As produções comportam as áreas de assentamento, as comunidades rurais, os sindicatos e associações, as escolas do campo, as salas de aula, as universidades e seus cursos de formação, como principais loci para a realização dos estudos.

Em geral, na leitura dos documentos, percebemos a adoção de uma perspectiva teórico-meto- dológica notadamente política, o que é relevante, na medida em que se indaga de frente à suposta neutralidade científica e também destaca o crescimento de pesquisadores engajados na educação do campo, não simplesmente na tendência acadêmica, mas no fazer ciência com os povos do campo.

Sabemos que há problemas e fragilidades encontradas nos textos (de natureza teórico-metodológica, dentre outras), no entanto, pensamos que não é nosso objetivo descrevê-las, pois o que pretendemos e fizemos foi inventariar o conhecimento exercido sobre educação do campo, na pesquisa em educação, da Região Nordeste.

\section{5 | CONSIDERAÇÕES FINAIS}

Este artigo vislumbrou evidenciar a produção científica sobre a educação do campo, na pesquisa em educação da Pós-Graduação em Educação da Região Nordeste.

Como considerações dentro do quadro analisado, enfatizamos que a pesquisa sobre educação do campo, na Pós-Graduação em Educação da Região Nordeste, cresceu significativamente nos últimos anos (1998 - 2015). Entendemos que o aumento da quantidade de cursos e programas, no entorno citado, contribuiu na delineação do cenário apresentado. Ao identificarmos o aumento na demanda de cursos, cresce em contrapartida a quantidade de investigações, bem como se polarizam as temáticas, as metodologias investigativas e o conhecimento científico. 
Não podemos desconsiderar que a visibilidade que a educação do campo vem conseguindo concretizar no cenário social e educacional do país, nos últimos anos, também tem aguçado o olhar de pesquisadores no campo da educação e de outras áreas do conhecimento sobre o tema.

As temáticas investigativas, presentes nas teses e nas dissertações, se assentam em um terreno que é vivenciado e sentido pelas comunidades do campo. É notório que os problemas e a realidade da formação de professores, das políticas educacionais e as questões que envolvem os movimentos sociais do campo, o currículo, a educação rural, a educação profissional, as escolas do campo e as juventudes no campo trazem inquietações para o futuro dos povos do campo no Brasil, culminando em pesquisas que patenteiam diferentes realidades.

Da mesma forma, as tendências teóricas existentes circunscrevem pesquisadores que estão ativos no movimento educativo do campo. As obras traduzem estudos arrolados que se somam no rol de conhecimentos da educação campesina, clarificando os investigadores iniciantes na Pós-Graduação em Educação. No entanto, podemos validar que a ausência de gêneros textuais acadêmicos, tais como teses, dissertações, artigos, dentre outros, nas produções, pode fragilizar a qualidade das publicações.

No tocante aos aspectos metodológicos dos trabalhos acadêmicos analisados, apontamos que há elementos negativos nos estudos. Eles se referem à caracterização dos caminhos metodológicos das investigações. Muitos trabalhos não demarcam os procedimentos investigativos e ofuscam o entendimento de procedimentos que validam a pesquisa científica.

Em um panorama geral, pensamos que as publicações enriquecem o conhecimento no campo da educação do campo. Os olhares dos pesquisadores trazem investigações significantes que aos poucos afirmam essa modalidade educativa na universidade e desenham um novo cenário epistêmico para os povos do campo.

Por fim, expressamos que o mapa elucidado a respeito da produção de conhecimentos acerca da educação do campo, na Pós-Graduação em Educação da região em cena, aponta caminhos, mas não preenche as lacunas existentes no projeto de um conhecimento mais abrangente e mais profundo da educação do campo no país. É preciso buscar outras trilhas para a pesquisa sobre educação campo. O campo é plural e nele habitam homens e mulheres que se concretizam na diversidade de ser humano, respingando diretamente em sua educação. 


\section{Referências}

ARROIO, M.; CALDART, R. S.; MOLINA, M. C. (Org.). Por uma educação no campo. Petrópolis, RJ: Vozes, 2008.

BRASIL. Decreto n 7.352, de 04 de novembro de 2010. Dispõe sobre a política de educação do campo e o Programa Nacional de Educação na Reforma Agrária PRONERA. Diário Oficial da União, Brasília, DF, 5 nov. 2010. Disponível em: <http://www.planalto.gov.br/ccivil_03/_ato2007-2010/2010/decreto/d7352.htm>. Acesso em: 27 maio 2015.

Lei $n^{\circ}$ 9.394, 20 de dezembro de 1996. Estabelece as diretrizes e bases da educação nacional. Diário Oficial da União, Brasília, DF, 23 dez. 1996. Disponível em: <http://www.planalto.gov.br/ccivil_03/Leis/L9394. htm>. Acesso em: 29 set. 2015.

. Resolução CNE/CEB n 1 , de 3 de abril de 2002. Institui Diretrizes Operacionais para a Educação Básica nas Escolas do Campo. Diário Oficial da União, Brasília, DF, 9 abr. 2002. Seção 1, p. 32. Disponível em: $<$ http://portal.mec.gov.br/cne/arquivos/pdf/CEB012002. pdf>. Acesso em: 30 maio 2015.

Resolução CNE/CEB, n 4, de 13 de julho de 2010. Define Diretrizes Curriculares Nacionais Gerais para a Educação Básica. Diário Oficial da União, Brasília, DF, 14 jul. 2010. Seção 1, p. 824. Disponível em: <http:// portal.mec.gov.br/dmdocuments/rceb004_10.pdf>. Acesso em: 30 jun. 2015.

. Resolução CNE/CP n ${ }^{\circ} 2$, de $1^{\circ}$ de julho de 2015. Define as Diretrizes Curriculares Nacionais para a formação inicial em nível superior (cursos de licenciatura, cursos de formação pedagógica para graduados e cursos de segunda licenciatura) e para a formação continuada. Diário Oficial da União, Brasília, DF, 2 jul. 2015. Seção 1, p. 8-12. Disponível em: <http://www.cref14.org.br/boletin/ res_cne_cp_002_03072015.pdf>. Acesso em: 29 set. 2015.

CALDART, R. S. Educação do Campo. In: CALDART, R. S. et al. (Org.). Dicionário da Educação do Campo. Rio de Janeiro: Escola Politécnica de Saúde Joaquim Venâncio; São Paulo: Expressão Popular, 2012.

CHARLOT, B. Relação com o saber, formação dos professores e globalização: questões para a educação hoje. Porto Alegre: Artes Médicas, 2005.

DAMASCENO, M. N.; BESERRA, B. Estudos sobre Educação Rural no Brasil: estado da arte e perspectivas. Revista Educação e Pesquisa, São Paulo, v. 30, n. 1, p. 97-118, jan./abr. 2004.

FERNANDES, B. M. Questão Agrária, Pesquisa e MST. São Paulo: Cortez, 2006.
FERREIRA, N. S. de A. As pesquisas denominadas "estado da arte". Revista Educação \& Sociedade, ano 23, n. 79, p. 257-272, ago. 2002.

GATTI, B. A. Formação de professores e carreira: problemas e movimentos de renovação. 2. ed. Campinas: Autores Associados, 2000.

LEITINHO, M. C.; DIAS, A. M. I. O estado da arte dos estudos curriculares nas Regiões Norte e Nordeste: ementário de disciplinas, temáticas investigativas e contribuições à área. In: GOMES, A.; LEAL, T. F. (Org.). Pesquisas em educação nas Regiões Norte e Nordeste: balanço e perspectivas. Recife: Editora da UFPE, 2014.

MEDEIROS, E. A. de. Do campo à universidade: histórias, saberes, experiências, fazeres e a formação no curso de licenciatura Pedagogia da Terra. 2013. Dissertação (Mestrado em Educação)- Universidade do Estado do Rio Grande do Norte, Mossoró, 2013.

MEDEIROS, E. A. de; AGUIAR, A. L. O. Educação do/no campo: história, memória e formação. Revista Educação: teoria e prática - UNESP, v. 25, n. 48, p. 06-18, jan./abr. 2015.

MINAYO, M. C. de S. (Org.). Pesquisa social: teoria, método e criatividade. 26. ed. Petrópolis, RJ: Vozes, 2007.

MOLINA, M. C. (Org.). Educação do campo e pesquisa: questões para reflexão. Brasília: Ministério do Desenvolvimento Agrário, 2006.

MOLINA, M. C.; HAGE, S. M. Política de formação de educadores do campo no contexto da expansão superior. Revista Educação em Questão, Natal, v. 51, n. 37, p. 121146, jan./abri. 2015.

OLIVEIRA, M. C. de P. Educação do campo: um estudo sobre o desenvolvimento do programa Escola Ativa em Marcelino Vieira/RN. 2013. Dissertação (Mestrado em Educação)- Universidade do Estado do Rio Grande do Norte, Mossoró, 2013.

SAVIANI, D. História das ideias pedagógicas no Brasil. Campinas: Autores Associados, 2007.

SILVA, S. P.; NOBREGA-THERRIEN, S. M.; FARIAS, I. M. S. de. Produções sobre a formação de professores no EPENN: análise do período 2003 a 2011. In: ENCONTRO DE PESQUISA EDUCACIONAL DO NORTE E NORDESTE, 21., 2013, Recife. Anais... Recife: UFPE, 2013.

STÉDILE, J. P. A questão agrária hoje. 3. ed. Porto Alegre: Universitária/UFRGS, 2002.

WANDERLEY, L. E. W. Educação popular: metamorfoses e veredas. São Paulo: Cortez, 2010. 